EGU21-1298

https://doi.org/10.5194/egusphere-egu21-1298

EGU General Assembly 2021

(c) Author(s) 2021. This work is distributed under

the Creative Commons Attribution 4.0 License.

\title{
Influence of land-use on the dynamics, quantity and composition of the organic matter transported across estuaries
}

\author{
E. Elena Garcia-Martin ${ }^{1}$, Richard Sanders ${ }^{1,2}$, Chris D. Evans ${ }^{3}$, Vassilis Kitidis ${ }^{4}$, Dan J. Lapworth ${ }^{5}$, \\ Andrew P. Rees ${ }^{4}$, Bryan Spears ${ }^{6}$, Andy Tye ${ }^{7}$, Jennifer L. Williamson ${ }^{3}$, and Daniel J. Mayor ${ }^{1}$ \\ ${ }^{1}$ National Oceanography Centre, Ocean BioGeosciences, Southampton, United Kingdom of Great Britain - England, \\ Scotland, Wales (elencia@noc.ac.uk) \\ ${ }^{2}$ NORCE Norwegian Research Centre, Bjerknes Center for Climate Research, Bergen, Norway \\ ${ }^{3}$ UK Centre for Ecology \& Hydrology, Environment Centre Wales, Deiniol Road, Bangor LL57 2UW, UK \\ ${ }^{4}$ Plymouth Marine Laboratory, Prospect Place, Plymouth, PL1 3DH, UK \\ ${ }^{5}$ British Geological Survey, Maclean building, Wallingford, OX10 8BB, UK \\ ${ }^{6}$ UK Centre for Ecology \& Hydrology, Bush Estate, Penicuik, EH26 0QB, UK \\ ${ }^{7}$ British Geological Survey, Environmental Science Centre, Keyworth, Nottingham, NG12 5GG, UK
}

The flux of terrigenous organic carbon across estuaries is an important and changing component of the global carbon cycle, but it is poorly understood. It has been proposed that estuaries can act either as a transporter of terrestrial dissolved organic carbon (DOC) to the ocean or as a reactor system in which DOC can be buried or transformed into carbon dioxide and released to the atmosphere. However, there is no clear understanding of the factors that drive estuaries to behave in one way or the other. Here we present the results from a study conducted in thirteen British estuaries which drain catchments of diverse land-uses under different hydrological conditions. Our data show that land-use influences the composition of the dissolved organic matter (DOM), the mixing dynamics of DOC and the quantity of DOC exported off the estuaries. Estuaries, whose catchments are less intensively managed and represent more natural ecosystems (average proportion of arable and (sub)-urban land-use $\sim 12 \%$ ), contain a higher proportion of biologically-refractory "humic-like" DOM, which is transported conservatively across the salinity gradient. In contrast, estuaries whose catchments are more intensively managed (average proportion of arable and (sub)-urban land-use 32\%) contain a high fraction of "proteinlike" DOM which is transported non-conservatively, and thus suggest the existence of additions and removal processes across the salinity gradient. Furthermore, estuaries with more intensively managed catchments tend to export more DOC to coastal areas than they receive from rivers. Our results indicate that future changes in land-use have the potential to alter aquatic fluxes of terrigenous DOM and the fate of the constituent carbon. 